\title{
Cartography teaching and the development of spatial thinking in Brazilian geography textbooks
}

\author{
Ronaldo G. Duarte \\ ${ }^{a}$ University of the State of Rio de Janeiro (UERJ), Rio de Janeiro, RJ, Brazil; duarte.rg@gmail.com
}

\begin{abstract}
Spatial thinking has been recognized as closely related to tools of representation (NRC, 2006) and the maps have been widely pointed out as crucial for the development of that kind of reasoning. Furthermore, the scientific community dedicated to the field of the spatial thinking has been asserting that the abilities encompassed in such a complex cognition can and must be fostered in school. Considering these groundwork, our research focused on the decision to assess the effectiveness of the contribution for the development of student's spatial thinking, provided by the questions found in Brazilian middle school geography textbooks. The main concern was the proficiency regarding cartographic language.

To assure the possibility of comparing our results with some other investigations we decided to use a methodology that was strongly based on the Taxonomy of Spatial Thinking, designed by Injeong Jo and Sarah Bednarz (2009).

Counting on those powerful tools we analyzed 6.884 questions in the three most adopted geography textbooks sets in Brazilian middle schools (6th, 7th, 8th and 9th grades). For the purpose of enlarging the number of books and countries to be compared, we have also evaluated 2.073 questions that are present in a French geography textbook set edited for the same grades. Using the taxonomy enabled us not only to evaluate if the questions demanded or not the use of the spatial thinking by the students. It also showed us the three general levels of reasoning involved, allowing to discern between low, intermediate and high levels of spatial thinking.
\end{abstract}

Keywords: Cartography teaching, Geography Education, Spatial Thinking, Geography Textbooks

\section{Introduction}

The author of this paper is one of many researchers who believe that Geography Education and School Cartography have both great importance for the development of spatial thinking among students in K-12. This dimension of intelligence is crucial for citizenship and for the practice of many professional and daily activities. Considering such a framework, the main goal of this research is to assess the contribution of geography Education and School Cartography in Brazilian middle school to enhance student's capacity to think spatially in situations that encompass spatial representations, specially cartographic ones, in geographical contexts. To answer this question, we decided to betake the field research known as "spatial thinking", developed mostly in the U.S. during the last two decades. As a consequence, we adopted the definition of spatial thinking that was presented in the report of the National Research Council (2006), which has become the main reference in the field: "Spatial thinking-one form of thinking - is based on a constructive amalgam of three elements: concepts of space, tools of representation, and processes of reasoning" (NRC, 2006, ix).

Our methodology was based the analysis of the three most adopted geography textbooks sets for the four years of Brazilian middle school (6th to 9th grades) with the purpose of assessing in which extent the exercises in those books are capable of fostering student's spatial thinking. To assure the possibility of comparing our results with some other investigations we decided to use a methodology that was strongly based on the Taxonomy of Spatial Thinking, designed by Injeong Jo and Sarah Bednarz (2009). The authors engineered the taxonomy in an effort aiming to provide a valuable tool precisely to assess the contribution of textbooks for the development of spatial thinking. They used their tool to evaluate university world geography textbooks in the United States and, a few years later, Scholz, Huynh, Brysch e Scholz, (2014) employed the same methodology with high school geography textbooks in the U.S. In our methodology, we have also considered the important contributions of Phil Gersmehl (2014) to the field.

Using such a valuable taxonomy enabled us not only to evaluate if the questions demanded or not the use of the spatial thinking by the students. I also showed us the three general levels of reasoning involved, allowing to discern between low, intermediate and high levels of spatial thinking.

The final data allowed us to stablish a lot of comparisons between French, Brazilian and American geography textbooks, regarding their potential to contribute for the development of spatial thinking specially through cartographic representation of the space. 


\section{Methodology uses to analyze questions and activities found in the textbooks}

\subsection{Jo and Bednarz"s Taxonomy}

In this work, we are based on the methodology developed and applied by Jo and Bednarz (2009) and replicated by Scholz, Brysch, Huynh, Scholz (2014). This methodology is the only known theoretical effort to measure, with a solid scientific foundation, the required level of spatial thinking present in the questions and activities of geography textbooks. Essentially, it is a matter of adapting and applying the taxonomy, to the analysis of exercises and activities found in geography textbooks used by 6 th to 9 th graders. The main purpose is to assess the percentage of those exercises and activities that effectively demand the use of spatial thinking, as well as the cognitive level required.

However, the methodology that will be adopted is not limited to identify if the question demand or not spatial thinking. It also includes a very important feature, which is the complexity of the cognitive operations involved in solving the problem. Jo, Bednarz and Metoyer (2010) emphasize that not every question helps developing students' thinking, and, specially, spatial thinking. Only questions that demand higher levels of reasoning fulfill this role of ex-tending the capacity to think in different dimensions:

This is similar to the understanding of Brazilian authors, like Castellar and Vilhena:

Whatever are teachers' conceptions of learning, they should take into account activities that motivate reasoning and cognitive abilities, connecting the subjects to students' daily lives. (...) This means that the same subject can be used to foster different levels of complexity through the activities and exercises. In other words, we can begin developing simple learning situations and, step by step, complex ones. Activities proposed by teachers, even those based on text-books, should be challenging and creative (...) (CASTELLAR and VILHENA, 2010, 140 , our translation).

Corroborating the statements above, we understand that, if it is true that exercises and activities in geography textbooks are a powerful tool to foster students' spatial thinking, it is logical to state that assessing the proportion of these exercises and activities that effectively need/stimulate spatial thinking is a valid proxy variable to judge in which extent geography textbooks are contributing to student's development of this kind of thinking. This state-ment is reinforced by the fact that textbooks represent the main didactic tool for most Brazilian teachers.

The main aspect of the methodology developed by Jo and Bednarz (2009) is the design of a taxonomy to classify the questions according to the level of spatial thinking involved in its solution. The taxonomy is structured around the three dimensions of spatial thinking: spatial concepts, tools of representation and processes of reasoning. From the taxonomy, it is possible to classify each question or pedagogical activity into 24 cells, according to the use or not use of spatial thinking and according to the level of complexity / abstraction of each question.

\subsection{Our version of Jo and Bednarz's Taxonomy}

Despite the broad and solid theoretical foundation concerning the taxonomy created by Jo and Bednarz, we decided to do not apply it ipsis literis in our analysis. Thus, we will not classify each question on a growing scale of spatial thinking complexity, which ranges from 1 to 24 , as proposed by the pair of researchers. The reason for this resolution is due to the controversy surrounding the decision of the authors to hierarchize the spatial concepts in primitive, simple and complex.

One of the main authors in the field of spatial thinking research, Phil Gersmehl, opposes himself to this kind of hierarchy, considering that complexity is linked to the application of the spatial concept and not to the concept it-self. However, we will maintain in our methodology an important feature of Jo and Bednarz's taxonomy, that is, the hierarchy of processes of reasoning involving spatial thinking. We will use the classification already presented: level of entry, for the simplest cognitive operations, of processing, for intermediate ones and output, for advanced.

We are, therefore, interested not only in measuring the proportion of questions in Brazilian textbooks that involve the need to use space thinking by students but also in assessing what cognitive level is required from these students to solve those questions. Thus, our methodological option approaches the schematic simplification made by Scholz, Huynh, Brysch and Scholz (2014), but with an important difference. In order to discriminate the use of maps as instruments for the development of spatial thinking through the questions presented in textbooks, it was necessary to add a record to the methodology of the American authors. Once we identified that a particular question involved spatial thinking, we recorded in which of the five types of representation of / in space it was framed in: 1 Cartographic Representations: Maps, plants, top-charts, etc..; 2 - Photographs; 3 - Graphics; 4 - Anamorpho-sis; 5 - Others: satellite images, cartoons, comics, drawings, representations of paintings, etc. Thus, our final workflow to classify the questions present in the textbooks analyzed is shown in Figure 1.

Simplified flowchart to apply Jo and Bednarz Taxonomy 


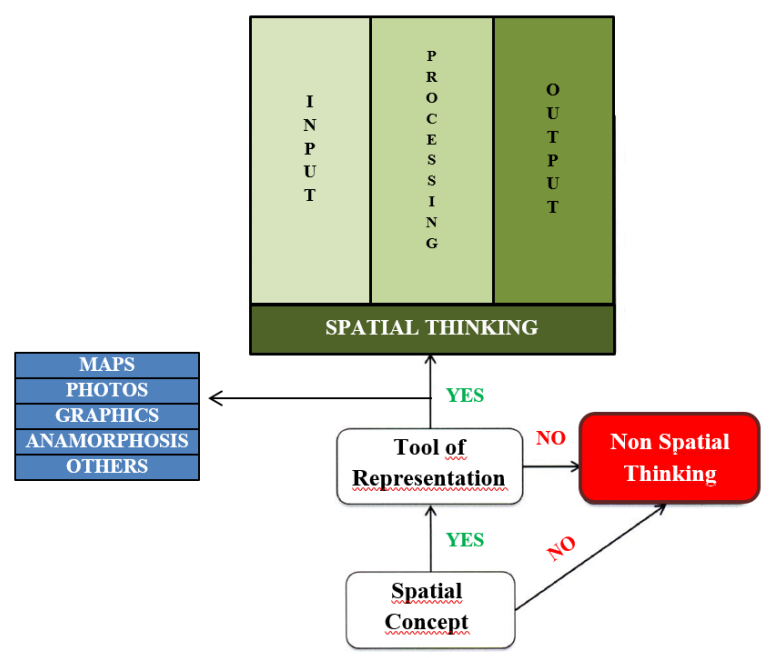

Fig. 1 - Designed by the author based on Scholz, et al. (2014, 216)

\section{Analyzing the Textbooks}

\subsection{The analyzed textbook bundles}

We have applied the methodology presented in the previous section to the three most adopted Brazilian sets of geography textbooks designed to Brazilian 6th to 9th grades of elementary school in the year of 2014: PROJETO ARARIBÁ; EXPEDICÕES GEOGRÁFICAS; PROJETO TELÁRIS.

In an effort to increase the comparison with the international scenario (in addition to the North American books analyzed by Jo and Bednarz and Scholz et al) we have decided to include the analysis of a French bundle of text-books designed to the same student's age of the Brazilian ones. It is the Histoire-Géographie set, under the direction of Vincent Adoumié (in front of a group of seven co-authors) and edited by Hachette Éducation. Of course, we have scrutinized only the questions in the chapters concerning the subject of Geography.

In Brazilian textbooks bundles, a total of 6,884 questions were analyzed and cataloged, according to the methodology already presented, and in the French books we assessed 2.073 questions. These numbers are considerably higher than the overall figures found in the survey conducted by Scholz, Huynh, Brysch and Scholz (2014), which ranked 720 questions, and the amount scrutinized by Jo and Bednarz (2009) with significant 3,010 questions. The main explanation for such a difference is quite simple. In each one of the American works, the researchers looked at four volumes of different authors, while in our research we examined three Brazilian and one French bundles, each one comprising four volumes, adding up to 16 units. The total number of questions found in French books, 2073, is compatible with the average found in Brazilian ones.

\subsection{Demanding or not demanding spatial thinking: an overview}

In this section, we will make a comparative analysis between textbooks of Brazil, France and the United
States, in terms of whether or not is necessary to use spatial thinking to solve the problems in those questions and their level of complexity according to the classification based on Jo and Bednarz's Taxonomy (2009). The first analysis involves only the binary use or non-use of spatial thinking. The overall results are displayed in Chart 1.



CHART 1 - Percentage of questions demanding spatial thinking

The first highlight of the chart is the very high percentage of spatial thinking questions found in the French set of books. On the other hand, the Brazilian sets are in the worst position regarding such a key feature in our research. In addition, it is necessary to contextualize the results of the American surveys. In the first place, it can be argued that the Brazilian percentage is not so bad, if we consider that the US didactic manuals were aimed at high school and university levels, while the Brazilian sets were designed to lower educational grade levels. There is no doubt that this is a valid and coherent argument.

However, it is important to make it clear that the percentages of questions that require spatial thinking in US textbooks are far from ideal. Consider the comment of the authors of one of these surveys:

This study reveals that the three components of spatial thinking are rarely integrated in the majority of textbook questions. There is a need for the development of more questions that guide students to synthesize the three components.. (JO e BEDNARZ, 2009, 10)

Researches aiming to evaluate the development of reason in questions present in geography textbooks are very reduced and, in this way, an adequate minimum percentage of this type of question have not been established. In addition, it is clear that there would be no point in arguing that all the exercises and activities found in those publications should require the use of spatial thinking, as presented here, following the NRC definition (2006). There is no doubt that very important questions for students' cognitive development and understanding of geographic space that do not always require the support of a tool of representation and a spatial concept. To grasp the concept of a global city, for example, does not necessarily demand a spatial representation tool, although it can be enriched by it.

In addition, languages other than imagery are also very important for this cognitive dialogue with reality. This is the case, for example, of written textual language and numeracy. However, there is no other discipline in the basic school whose primary purpose is to spatially literate 
the student, in the perspective of understanding the space constructed in the social-nature dialogue. Even with the help of other disciplines in this task, only Geography prioritizes this mission. Thus, it seems to us quite reasonable to say that, if what is expected from a geography textbook is not the one hundred percent questions demanding the use of spatial thinking, it is also not satisfactory to have only 20 or 30 percent of questions and activities with such a feature.

A second layer of our research concerns the three levels of reasoning, as defined in the taxonomy created by Jo and Bednarz. The three levels (input, processing and output) are hierarchical based on the command verbs of questions and activities. It is good to reaffirm that the data presented, both those of our surveys and those obtained from the North American research's, are the result of the classification carried out only with the questions that effectively involve spatial thinking. The data of the American books presented in chart 2 were taken from the research's conducted by Jo and Bednarz (2009) and Scholz et al (2014).

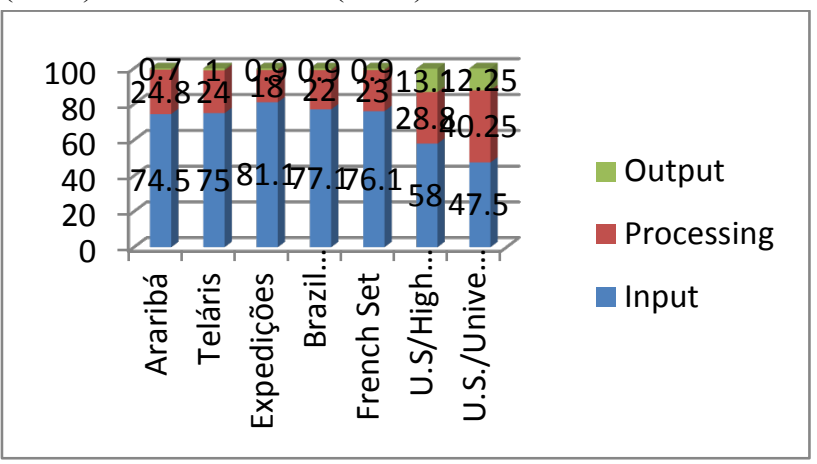

CHART 2 - Cognitive level of questions demanding spatial thinking $(\%)$

At first glance, a comparative analysis that considers the three levels proposed by Jo and Bednarz, seems to point out to a certain coherence between the didactic sets evaluated in the three countries and the ages of the students to whom the books were intended. The Brazilian and French sets, designed to younger students have a strong predominance of questions involving simpler cognitive operations (input), while the North American ones (designed to high school and to university education) present considerably larger proportions of processing and exit questions.

Nevertheless, the numerical equivalence between the average of the Brazilian sets and the one registered in the French set, as well as the proportional distribution of the questions by the three cognitive levels considered, can not leave us to forget three important points. The first is the fact that, while the French set uses a form of space representation in about $67 \%$ of the questions, Brazilian sets only use these same representations in $23 \%$. That is, the use of tools of representation, specially maps, in Brazilian textbooks is much smaller than the evaluated European set, despite the fact that the average cognitive level of the questions is similar for all the sets.

The second point is that $56.7 \%$ of the French questions demand the student's spatial thinking, while the average of the three Brazilian sets is $22 \%$ only. In other words, the French set shared with Brazilian ones the high proportion of input questions, but in a context in which the French students are led to use spatial thinking much more often. This difference can not be disregarded in our comparison.

The third and final point is to remind ourselves that the authors of the two American surveys considered as very low the percentages of questions that require spatial thinking and the ratio of questions with more advanced cognitive levels. Therefore, we are not comparing the percentages of the Brazilian and French sets of textbooks with the ideal percentages of cognitive exercise of spatial thinking in US books. We are referring to the average data considered unsatisfactory by the authors of the mentioned articles. Therefore, the very high percentage of "entry" ques-tions in the sets that we have evaluated is a powerful expression of how much need to be done in all these countries, regarding the development of student space thinking through textbooks.

\subsection{General analysis of questions that require spatial thinking using cartographic documents}

Although our research has considered all kinds of tools of representation that could be integrated into one (or more) spatial concepts to classify a question as whether or not related to spatial thinking, in this part of the text we will prioritize the analysis of the data associated with questions that develop the student's spatial thinking using a cartographic document as a tool of representation.

In this work, we will be circumscribed to the four textbook sets analyzed by us, since the tabulation of the text-book questions referring to the two North American works followed the binary pair "use or not use of space representation" without discriminating the type of representation for the first case. We, instead, took care of making such discrimination, following the methodology represented in the flow chart of Figure 1. The general data can be seen in Table 1 .

\begin{tabular}{|c|c|c|c|c|c|c|}
\hline \multirow[t]{2}{*}{$\begin{array}{l}\text { Textboo } \\
\text { k Sets }\end{array}$} & \multicolumn{2}{|c|}{$\begin{array}{l}\text { Maps in } \\
\text { the four } \\
\text { volumes of } \\
\text { each set }\end{array}$} & \multicolumn{4}{|c|}{$\begin{array}{l}\text { Maps linked to questions } \\
\text { demanding spatial thinking }\end{array}$} \\
\hline & $\begin{array}{l}\text { To } \\
\text { tal }\end{array}$ & $\begin{array}{l}\text { Perc } \\
\text { entag } \\
\text { e of } \\
\text { all } \\
\text { imag } \\
\text { es }\end{array}$ & $\begin{array}{l}\mathrm{T} \\
\text { ot } \\
\text { al }\end{array}$ & $\begin{array}{l}\text { Perce } \\
\text { ntage } \\
\text { of all } \\
\text { questi } \\
\text { ons }\end{array}$ & $\begin{array}{l}\text { Perc } \\
\text { enta } \\
\text { ge of } \\
\text { all } \\
\text { maps }\end{array}$ & $\begin{array}{l}\text { Percentag } \\
\text { e of all } \\
\text { questions } \\
\text { demandin } \\
\text { g spatial } \\
\text { thinking }\end{array}$ \\
\hline $\begin{array}{l}\text { ARARI } \\
\text { BÁ }\end{array}$ & $\begin{array}{c}41 \\
6\end{array}$ & $\begin{array}{c}30,2 \\
\%\end{array}$ & $\begin{array}{l}2 \\
6 \\
4\end{array}$ & $\begin{array}{c}13,3 \\
\%\end{array}$ & $\begin{array}{c}63,5 \\
\%\end{array}$ & $58,4 \%$ \\
\hline $\begin{array}{l}\text { TELÁR } \\
\text { IS }\end{array}$ & $\begin{array}{c}24 \\
8\end{array}$ & $\begin{array}{c}21,3 \\
\%\end{array}$ & $\begin{array}{l}2 \\
6 \\
9\end{array}$ & $8,6 \%$ & $\begin{array}{l}108, \\
4 \%\end{array}$ & $57,8 \%$ \\
\hline $\begin{array}{l}\text { EXPEDI } \\
\text { ÇÕES }\end{array}$ & $\begin{array}{c}55 \\
2\end{array}$ & $\begin{array}{c}32,1 \\
\%\end{array}$ & $\begin{array}{l}4 \\
3 \\
6\end{array}$ & $\begin{array}{c}24,5 \\
\%\end{array}$ & $\begin{array}{c}78,9 \\
\%\end{array}$ & $76,8 \%$ \\
\hline $\begin{array}{l}\text { FRENC } \\
\text { H }\end{array}$ & $\begin{array}{c}43 \\
4\end{array}$ & $\begin{array}{c}37,8 \\
\%\end{array}$ & $\begin{array}{l}6 \\
\mathbf{2}\end{array}$ & $\begin{array}{c}30,0 \\
\%\end{array}$ & $\begin{array}{l}142, \\
9 \%\end{array}$ & $52,7 \%$ \\
\hline
\end{tabular}




\section{$|+| \mathbf{0}|\quad|$ \\ Table 1 - The relevance of maps for the development of spatial thinking in the analyzed textbooks sets}

Maps are the second most common type of spatial representation in Brazilian geography didactic sets examined by us (photographs are the first). On the other hand, they are the most used tool to develop spatial thinking. Once again, the textbook set coordinated by Vincent Adoumié, stands out in relation to Brazilian ones. It has the highest percentage of maps in relation to the total number of images in each set, both considering numerical proportion and the proportion of images used to develop spatial thinking, in relation to the iconography found in the textbooks.

In addition, the French collection presents the high percentage of $142.9 \%$ questions that use maps to develop spatial thinking. This proportion, incoherent at first sight, is explained by the fact that it is extremely common in these books to have more than one question based on the same map. Although not all activities linked to a map require the mobilization of a spatial concept (so as to classify it as a spatial thinking demander) the fact is that the pedagogical proposal of the French work includes the intense use of maps as a didactic resource. The result is this remarkable ratio of practically three spatial thinking questions for each two maps in the textbook set.

In comparison to those figures, we have to pay attention to the fact that two Brazilian sets present an average of less than one spatial question per map, and the other set has an average of one question per map. Considering that in those manuals there were also many cases where we can find more than one question linked to the same map, we can jump to the conclusion that there is still a small use of cartography as a didactic resource in general and a very reduced effectiveness of such a tool for the development of spatial thinking. To make things worse, we have verified that there are many maps without any kind of pedagogical use in those Brazilian textbooks.

\subsection{Level of processes of reasoning involved in questions that require spatial thinking with the use of maps}

In the more general evaluation of the textbook sets regarding the presence of questions that require spatial thinking, we took care to also evaluate the cognitive level demanded in those questions, according the Taxonomy of Jo and Bednarz. At this stage of our approach, focused on the relationship between cartography and spatial thinking in textbooks, we want to use this same layer of analysis to refine our conclusions. With this purpose, we will present data from the four sets analyzed in this research, referring specifically to the cognitive level verified in questions that demand spatial thinking based on maps. See Chart 3.

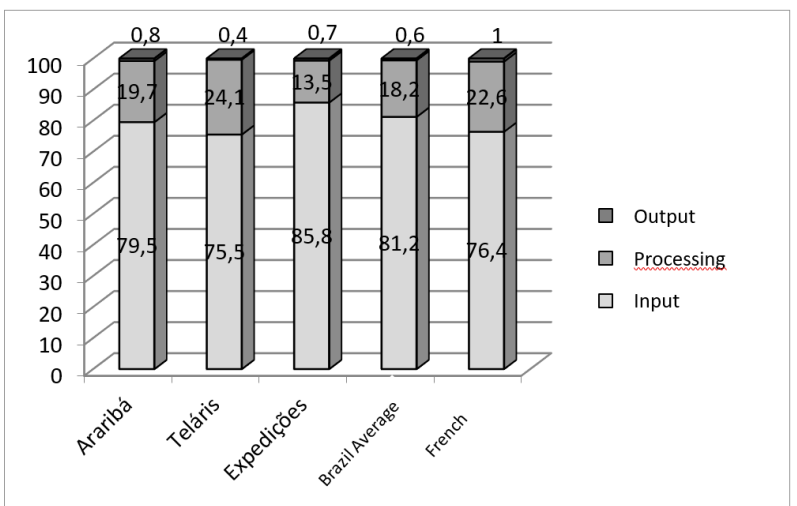

CHART 3 - Cognitive levels of questions demanding spatial thinking and based on cartographic documents - Average of textbook sets $(\%)$

Analyzing Chart 3 we can see that there are no significant changes in the cognitive level of questions involving spatial thinking and linked to the use of maps, in relation to what occurs with the same type of question involving all spatial representations, as we can figure by the comparison with Chart 2. Rooted on our theoretical foundations, the bibliography consulted and the surveys that we carried out, we evaluated that this scenario is quite negative, in view of the objectives of developing spatial thinking of students through cartography and geographic education.

We know that the age group for this type of textbooks (approximately between 11 and 14 years) is in the cognitive transition from the stage of concrete operations to the stage of formal operations, according to Piaget. In other words, students are beginning to develop their abstract rationale, and this also applies, of course, to the field of spatial thinking. Thus, it would be incoherent to expect that a large proportion of questions should demand complex cognitive operations, associated with the kind of spatial thinking that Jo and Bednarz have classified as "output": hypothesize, generalize, evaluate, predict, and so on. Even so, we consider that the insignificant percentage (equal to or less than one percent) of output questions signals the need to design activities that demand more sophisticated cognitive abilities, even if in a considerably lower proportion than the other two cognitive levels.

However, we understand that the focus of the problem that must now be addressed by the authors of Brazilian geography textbooks is connected to the very high proportion of cartography based questions that require only basic operative input skills such as naming, describing, identifying, recognize, observe, among others. The fact that between 75 and 85 percent of those questions fall within this cognitive level is, in our view, an unequivocal statement of the underutilization of cartography in the final years of Brazilian fundamental school (6th to 9th grades). This goes both to Brazilian as to French textbook sets. We know that, as we have already said, there is no serious scientific research that defines ideal parameters of proportionality, regarding spatial thinking question in textbooks for each school period. Nevertheless, it seems to be beyond dispute that 
the absolute preponderance of very simple questions in the sets we have examined is a clear evidence of how much needs to be done in the development of spatial thinking through cartographic activities in school.

Another problem related to this high average percentage of "entry" spatial questions is that the percentages remain practically unchanged throughout the school years. Look at the data in Chart 4.

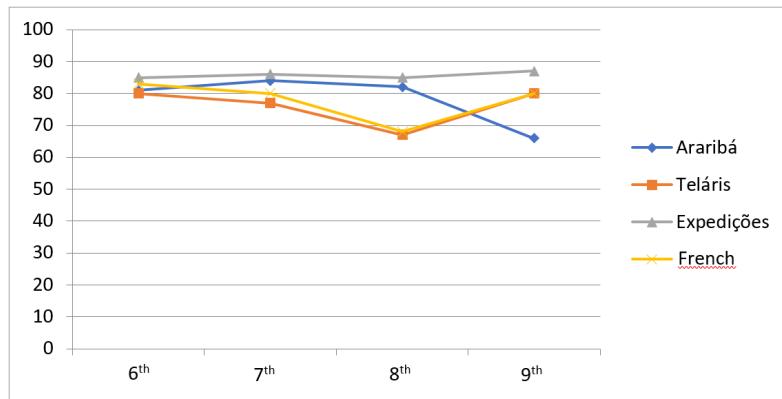

CHART 4 - Questions demanding spatial thinking and based on cartographic documents classified as "In-put" in each volume of textbook sets $(\%)$

At least in Brazil, it is coherent to associate this gap in modulating, gradually and incrementally, the complexity of students' spatial thinking through cartographic activities found in the textbooks, to another ancient and well-known problem regarding the teaching of cartography in Brazilian education: excessive concentration of cartography teaching only in the sixth year of elementary school, resuming the topic only in high school.

This practice inhibits the expansion of students' cartographic proficiency and makes it much more difficult to build more complex spatial questions based on maps, since the students did not deepen their capacity to operate with cartography at more complex levels. The main result is that students reach the high school level with very limited capacity to operate with maps as a cognitive resource to deal with problems in real life.

This whole scenario suggests that, so far, Brazilian geography textbook authors are no concerned about balancing the complexity level of cartography based questions throughout the four final years of fundamental education in Brazil. Undoubtedly, this lack of concern seriously compromises the advancement of students' cartographic proficiency and the development of their spatial thinking. Even more so if we consider that it is in this years (especially in the last two years) that students are being prepared to deal with the contents of high school, a period in which the demand for higher levels of abstraction and generalization is expected to be more intense.

Perhaps the greatest drawback of this simplicity of cartographic spatial thinking questions lies in the fact that much of these input questions were actually limited to request simple location of phenomena or spatial form, identify whether or not a given phenomenon was represented on a map, or even locate the city to calculate the time difference between them. Just to name a few examples: What is the title of the map? What is the significance of the predominance of green and blue colors in the north of the continent on this map? In what region of your municipality is your residence? What about your school? What are the Brazilian states cut by the Equator line? What mineral resources are found in the state where you live? On which island is the capital of the country located? Chart 5 ex-presses in numbers the sad reality we are describing.

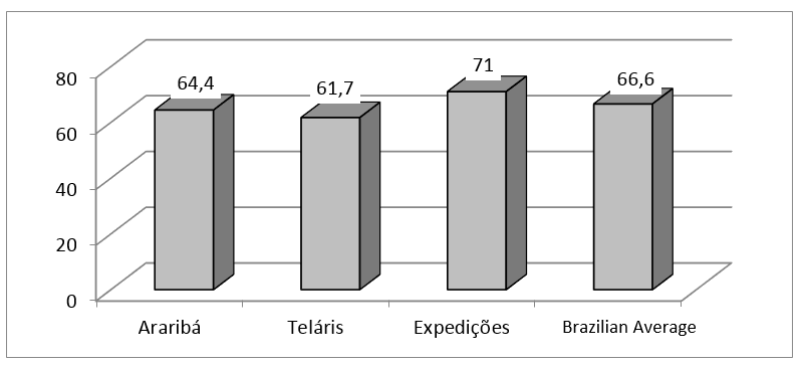

CHART 5 - Percentage of map based questions demanding spatial thinking and that are restricted to the action of locating and identifying phenomena

Before proceeding we want to emphasize that we are not suggesting the purge of questions involving localization of spatial phenomena with cartographic support. On the contrary, as James Dunn reminds us: "Location has always been valued in Geography" (2011, 82). Emphasizing that geography is always concerned with space, Phil Gersmehl $(2008,7)$ does not hesitate to state that "A geographer can borrow knowledge from other disciplines, but the focus is always the location of things, the conditions of places and the connections between places ". The author devotes three pages of a post-writing from the first chapter of his book "Teaching Geography" to what he defined as "Thoughts about the Little Word Where" (Gersmehl, 2008, 10-12).

In short, textbooks should rather contain questions involving the location of phenomena in maps, as this is a crucial starting point for the geographic science and teaching. But they can not, of course, be restricted to this kind of question. It should be noted that about two-thirds, on average, of map based questions found in the analyzed textbooks are limited to ask questions about the location of spatial phenomena, most of the times without any analytical development. It is a clear evidence related to the lack of efficiency of those textbook sets to promote the development of more advanced levels of spatial thinking associated with cartography to students in the final years of fundamental education.

\section{Conclusions}

Our data reveals that the activities and exercises present in the geography textbook sets designed for Brazilian 6th to 9 th grades are not prioritizing the development of students' spatial thinking. Our analysis pointed out five main causes to explain this scenario:

1)Small number of questions involving the connection between the three elements of spatial thinking.

2)Reduction in the amount of questions involving spatial thinking throughout the 6th to 9th grades. 
3)Low cognitive level demanded by questions that effectively operate with spatial thinking.

4)Inconsistent distribution of cognitive level of the number of questions that require the spatial thinking throughout the 6th to 9 th grades.

5)Very high proportion of questions that only require the student's ability to locate a phenomenon in a carto-graphic representation.

It is our understanding that those results and the related analysis will encourage teachers to be aware about the need to design more thoughtful questions addressing the issue of using cartography for the development of spatial thinking and will help then with the task. We do believe that it can cause the same effect on geography textbook authors.

\section{References}

CASTELLAR, S. M. V.; MORAES, J. V. (2010). Ensino de Geografia. São Paulo: Cengage Learning.

DUNN, J. M. (2011). Location Knowledge: Assessment, Spatial Thinking, and New National Geography Standards. Journal of Geog-raphy, 110:2, 81-89. http://dx.doi.org/10.1080/00221341.2010.511243.

Acessed 21 set. 2014.

GERSMEHL, P. Teaching Geography 2nd ed (2008). New York: Guilford Press.

GERSMEHL, P. Teaching Geography 3rd ed (2014). New York: Guilford Press.

JO, I.; BEDNARZ, S. (2009). Evaluating geography textbook questions from a spatial perspective: Using concepts of space, tools of representation, and cognitive processes to evaluate spatiality. Journal of Geography 108:4-13.

http://dx.doi.org/10.1080/00221340902758401 Acessed 5 set. 2013.

JO, Injeong; BEDNARZ, Sarah; METOYER, Sandra. Selecting and Designing Questions to Facilitate Spatial Thinking. The Geography Teacher, 2010, 7:2, 49-55. Disponível em: http://dx.doi.org/10.1080/19338341.2010.510779 (Acesso em 28/06/2013)

NATIONAL RESEARCH COUNCIL (2006). Learning to think spatially: GIS as a support system in the K-12 curriculum. Washing-ton: National Research Council Press. ISBN: 0-309-53191-8, 332 p. http://www.nap.edu/catalog/11019.html Acessed 3 jul. 2013.

SCHOLZ, Michael A., HUYNH, Niem Tu, BRYSCH, Carmen P., SCHOLZ, Ruojing Wang (2014). An Evaluation of University World Geography Textbook Questions for Components of Spatial Thinking, Journal of Geography, 113:5, 208-219. ISSN 0022-1341 